\title{
Sporadic pediatric severe familial adenomatous polyposis: A case report
}

\author{
ANDREA CERASUOLO ${ }^{1}$, ERASMO MIELE ${ }^{2}$, MARINA RUSSO $^{2}$, ANTONIETTA AVERSANO $^{3}$, \\ FRANCESCA CAMMAROTA $^{3,4}$, FRANCESCA DURATURO ${ }^{3,4}$, RAFFAELLA LICCARDO ${ }^{3}$, \\ PAOLA IZZO $^{3,4^{*}}$ and MARINA DE ROSA ${ }^{3,4^{*}}$
}

${ }^{1}$ Molecular Biology and Viral Oncology Unit, Istituto Nazionale Tumori IRCCS 'Fondazione G. Pascale'; Departments of ${ }^{2}$ Translational Medical Sciences, Section of Pediatrics and ${ }^{3}$ Molecular Medicine and Medical Biotechnology, University of Naples Federico II; ${ }^{4}$ Ceinge Biotecnologie Avanzate, I-80131 Naples, Italy

Received January 7, 2019; Accepted June 4, 2020

DOI: $10.3892 / \mathrm{mco} .2020 .2090$

\begin{abstract}
Familial adenomatous polyposis (FAP) is an autosomal dominant hereditary precancerous condition caused by germline pathogenetic variants in the tumor suppressor adenomatous polyposis coli $(A P C)$ gene. Patients with FAP develop multiple gastrointestinal adenomatous polyps usually at the age of 20 years, which, if untreated, become cancerous in $100 \%$ of cases. Genotype-phenotype associations have been extensively described; however, inter- and intra-familial variability exists. It is crucial to characterize the causative pathogenetic variant in each pedigree in order to develop a cancer prevention program and follow-up strategy for at-risk families. The present report describes a severe case of sporadic FAP that was diagnosed when the patient was $\sim 2$ years old. The patient was a carrier of the de novo pathogenic c.4132 C >T (p.Gln1378X) variant. Additionally, the patient was a carrier of the homozygous c.5465 T>A (p.Asp1822Val) polymorphism, inherited from both parents. However, it remains unclear whether or not this polymorphism is involved in the phenotypic manifestation. This case highlights the need to extend molecular screening to very young children when they show iron-deficiency, anaemia and/or rectal bleeding, even in the absence of a familial history of disease.
\end{abstract}

Correspondence to: Professor Marina De Rosa, Department of Molecular Medicine and Medical Biotechnology, University of Naples Federico II, via S. Pansini 5, I-80131 Naples, Italy

E-mail: marina.derosa@unina.it

*Contributed equally

Abbreviations: CRC, colorectal cancer; FAP, familial adenomatous polyposis; APC, adenomatous poliposis coli; EGD, esophagogastroduodenoscopy; SNPs, single nucleotide polymorphisms

Key words: colorectal cancer, pediatric early onset familial adenomatous polyposis, de novo germline $A P C$ gene variants

\section{Introduction}

Colorectal cancer (CRC) is the third most common cancer in men and the second in women, with 1.4 million estimated cases worldwide, and 700,000 estimated deaths $(1,2)$. Familial adenomatous polyposis (FAP) is an autosomal dominant pre-cancerous syndrome characterized by the development of hundreds to thousands of colorectal adenomatous polyps that, if untreated, lead to CRC in the third to fourth decade of life (3-5). According to the European Medicines Agency, in 2009 , there were 3-10/100,000 new cases in the European Union (6).

Germline pathogenic variants in the tumor suppressor adenomatous polyposis coli $(A P C)$ gene are responsible for FAP (7). De novo pathogenetic variants in $A P C$ are also found in the majority of sporadic cases of FAP $(8,9)$. The $A P C$ gene is located on chromosome $5 \mathrm{q}$ and encodes a $312 \mathrm{kDa}$ protein that is involved in several cellular processes, such as cell migration, adhesion and cell cycle regulation, as well as chromosome segregation, signal transduction and apoptosis $(10,11)$. The tumour suppressing activity of APC depends on its capacity to regulate $\beta$-catenin levels in the nucleus. In fact, in the absence of Wnt signalling, APC induces $\beta$-catenin degradation. If the extracellular Wnt signal is absent, APC-induced $\beta$-catenin degradation is inhibited, $\beta$-catenin accumulates in the nucleus and modulates gene transcription. Pathogenic variants that disrupt APC interaction with $\beta$-catenin are oncogenic (6-11).

The classical symptoms of FAP, including bleeding, diarrhoea and abdominal pain, are generally diagnosed at around 20-25 years of age. Genetic testing is performed to verify the clinical diagnosis and to identify asymptomatic carriers in affected families. Early FAP detection by genetic screening in at-risk families is crucial in order to implement effective prophylaxis strategies. Moreover, the results of genotyping should be considered together with clinical data to decide the type and time of surgery (12).

Various symptomatic young patients with a family history of FAP have been reported, however we describe a case of severe paediatric FAP caused by a de novo pathogenic variant. 


\section{Case report}

The patient described herein is a ten-year-old boy clinically diagnosed with FAP at the age of nine and recruited to the Ambulatorio di Pediatria of AOU Federico II of Naples in December 2016. The anamnesis revealed that symptoms, i.e. diarrhoea and rectal bleeding, first appeared at the age of two and became more frequent during late childhood. Colonoscopies and esophagogastroduodenoscopy performed in December 2015, December 2016, March 2018 and February 2019 showed hundreds of subcentimetre polyps throughout the colon (Fig. 1A) as well as polyps in the gastric fundus $(>10 \mathrm{~mm})$ and body $(<5 \mathrm{~mm})$ (Fig. 1B), respectively, thereby confirming the diagnosis of FAP. Histological analysis revealed a Helicobacter pylori infection-negative chronic gastritis-like inflammation of the stomach, inflammatory infiltrate in the ileum and low grade dysplasia of the glandular epithelium of the colon. Haematochemical analysis revealed microcytic anaemia with a haemoglobin level of $10.3 \mathrm{~g} / \mathrm{dl}$ and a mean cellular volume of $66.5 \mathrm{fl}$. The results of physical analysis were unremarkable. As shown in Fig. 2A, there was no family history of FAP, other polyposis syndromes or colon cancer. The patient's parents received clinical and genetic counselling and provided informed consent to molecular screening.

Genomic DNA was extracted from peripheral blood lymphocytes of the proband and his parents as previously described (13). Briefly, $2 \mathrm{ml}$ of the patient's blood were incubated at $37^{\circ}$ in a red blood lysis buffer $\left(0.15 \mathrm{M} \mathrm{NH}_{4} \mathrm{Cl}_{2}\right.$ and $0.17 \mathrm{M}$ Tris- $\mathrm{HCl}, \mathrm{pH}$ 7.65) for $15 \mathrm{~min}$ and centrifuged. The lymphocyte pellet was resuspended in a DNA extraction buffer (1 M Tris. $\mathrm{HCl}, 0.5 \mathrm{M}$ EDTA and $5 \mathrm{M} \mathrm{NaCl}$ ) and digested with Proteinase $\mathrm{K}$ and $10 \% \mathrm{SDS}$ at $60^{\circ} \mathrm{C}$ for ten minutes. After adding $6 \mathrm{M} \mathrm{NaCl}$, the sample was centrifuged, the DNA in the supernatant was precipitated with absolute ethanol and resuspended in an appropriate volume of deionized sterile water. The quality and the quantity of the DNA was spectrophotometrically assessed with the NanoDrop ${ }^{\mathrm{TM}} 2000$ spectrophotometer (Thermo Fisher Scientific, Inc.). An absorbance ratio at 260 and $280 \mathrm{~nm}$ in the range of 1.8-2.0 was considered good for further analysis.

$A P C$ exons 1 to 15 were amplified by polymerase chain reaction (PCR) using $100 \mathrm{ng}$ of the proband genomic DNA and primer pairs described by Groden et al (7) in a $50 \mu 1$ reaction mixture (Table I). The amplification protocol was as follows: $5 \mathrm{~min}$ at $95^{\circ} \mathrm{C}$, then 35 cycles of $20 \mathrm{sec}$ at $95^{\circ} \mathrm{C}, 30 \mathrm{sec}$ at $60^{\circ} \mathrm{C}$ and $45 \mathrm{sec}$ at $72^{\circ} \mathrm{C}$, and a final extension of $5 \mathrm{~min}$ at $72^{\circ} \mathrm{C}$. All reactions were run in the MyCycler thermal cycler (Bio-Rad). Amplified fragments were run on a $1 \mathrm{X}$ agarose gel and visualized with ethidium bromide, then purified using the QIAquick PCR Purification Kit (Qiagen) according to the manufacturer's recommendations and subjected to automated Sanger sequencing (Fig. 2B and C).

The sequences analysis was performed by alignment with those present in the GenBank database using the BLASTn software (http://www.ncbi.nlm.nih.gov/blast/html). The accession number of the used reference sequence was NM_000038.4. The same procedure was followed for the genetic analysis of $A P C$ exon 15 (fragment $\mathrm{H}$ ) on the DNA of both the patient's parents (Fig. 2B and C).
Genetic counselling excluded a family history of adenomatous polyposis syndrome. Indeed, the patient's parents reported that none of his first grade relatives, including themselves, had symptoms correlated to FAP or to those developed by the proband, such as chronic gastritis-like inflammation of the stomach in the absence of Helicobacter pylori infection. However, none of them underwent colonoscopy.

Sequence analysis of the $A P C$ gene revealed the causative pathogenetic variant in the proband: A heterozygous $\mathrm{C}$ to $\mathrm{T}$ transition in the exon 15H called c.4132 C>T (p.Gln1378X), which changes the glutamine at codon 1378 in a premature stop codon (Fig. 2C). The proband was also carrier of the rs459552, [c.5465 T>A (p.Asp1822Val)] polymorphism, in fragment L of exon 15 of the APC gene (data not shown). Such polymorphism causes the substitution of a valine with an aspartate at codon 1822 and is reported as benign in the ClinVar database (https://www.ncbi.nlm.nih.gov). Furthermore, the $A P C$ genetic carrier test for c.4132 $\mathrm{C}>\mathrm{T}$ (p.Gln1378X) mutation was negative in the proband's parents (Fig. 2C), whereas both carried the rs 459552 polymorphism.

\section{Discussion}

Approximately $70-80 \%$ of FAP cases are caused by inherited pathogenetic variants of the APC gene, whereas up to $25 \%$ of cases are attributed to de novo germline pathogenetic variants (3). Herein, we report the case of a ten-year old boy, clinically diagnosed with severe FAP, in the absence of a family history of polyposis. Genetic analysis of $A P C$ confirmed the clinical diagnosis. In fact, a stop codon variant, namely c.4132 $\mathrm{C}>\mathrm{T}$ (p.Gln1378X) in fragment $\mathrm{H}$ of exon 15 , was identified as the cause of FAP.

Although pathogenetic APC germline variants have a penetrance of $\sim 100 \%$, very close genotype-phenotype correlations and marked heterogeneity in the phenotypic expression of FAP are well known. Severe phenotypes, characterized by more than 5,000 polyps and early onset of the disease are associated with pathogenetic variants between codons 1250 and 1464, whereas patients with classical FAP develop hundreds to thousands of adenomatous polyps in the colorectum during the second and third decades of life $(14,15)$. Germline pathogenetic variants between codons 168 and 1680 and deletion of entire APC locus are responsible for classical FAP $(4,16)$. Attenuated phenotypes, characterized by a few polyps $(\sim 10-100)$ are associated with pathogenetic variants at the extreme $5^{\prime}$ or $3^{\prime}$ end of the $A P C$ gene or in alternatively spliced exon 9. Alterations in the region between codons 1286 and 1513, i.e., the mutation cluster region, probably provide a strong selective advantage to tumour cells. Indeed, the majority of somatic variants and germline $A P C$ variants are clustered in this region and cause aggressive phenotype $(4,16)$. Thus, in accordance with previous studies, our patient, who carried a pathogenetic truncating variant at codon 1378, had a very early onset of the disease and severe FAP phenotype $(17,18)$. The c. $4132 \mathrm{C}>\mathrm{T}$ variant is reported as somatic by Liu et al (19) and in the 'Catalogue of Somatic Mutations in Cancer (COSMIC)' (http://cancer.sanger. ac.uk/cosmic/mutation/overview?id=18862). However, Friedl and Aretz (20) found this variant as germlinal in a 

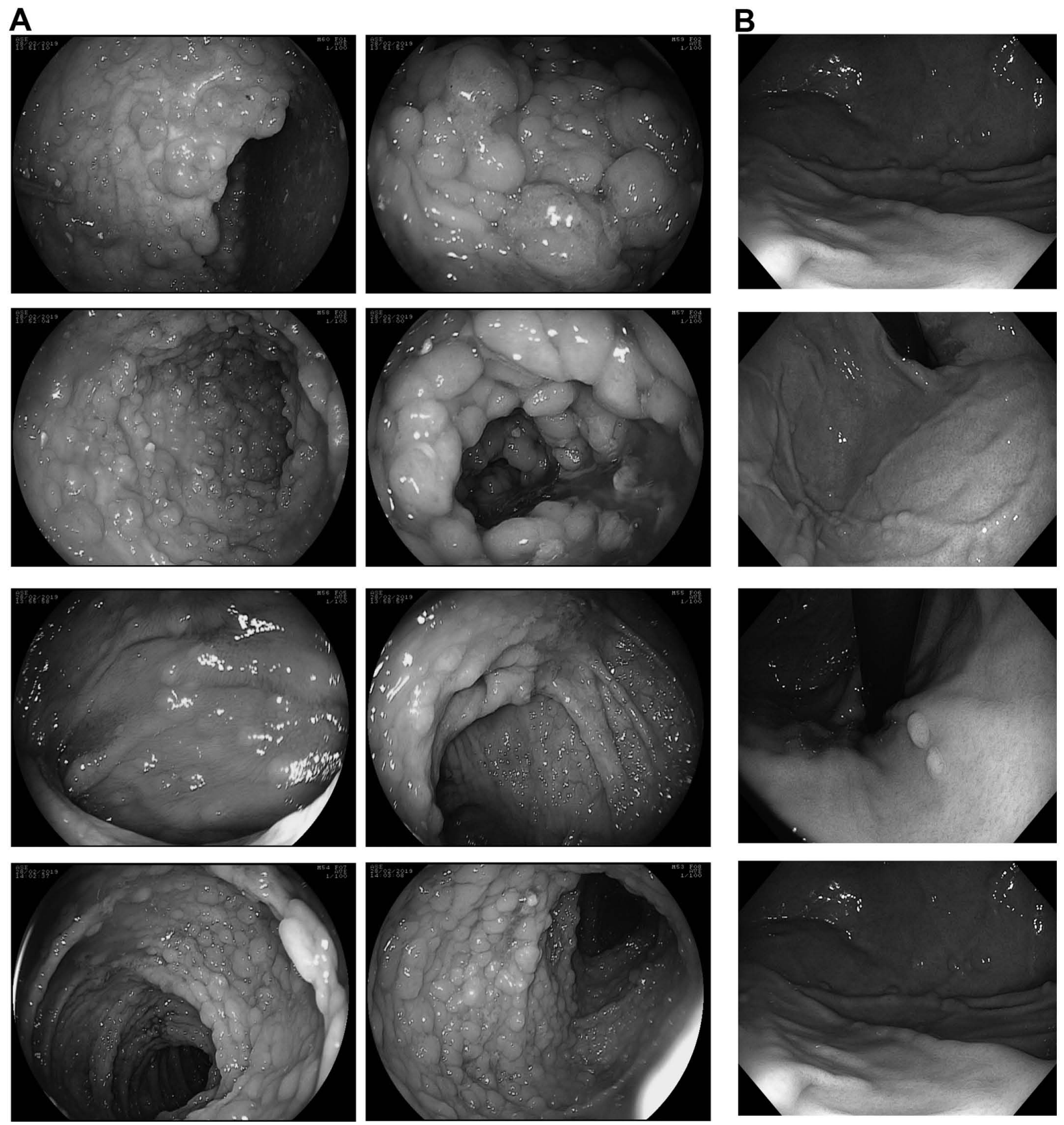

Figure 1. Clinical features of the proband. Colonoscopy and esophagogastroduodenoscopy performed during the last hospitalization in February 2019 revealed evidence of multiple (A) colorectal and (B) gastric adenomatous polyps.

FAP patient, but no information about the patient's history was provided (20). Moreover, to date, no genotype/phenotype correlations have been reported.

The patient also carried a second DNA variant, namely, c.5465 T>A (Asp1822Val). This polymorphism, which was also identified in the patient's parents, causes a valine/aspartate substitution at codon 1822. Several studies have investigated the role of polymorphisms in determining the risk of developing FAP or CRC, hypothesizing that the common variants in CRC genes now considered benign variants are, rather, low-risk alleles.

De Rosa et al (21) were the first to identify the Asp1822Val polymorphism. They analysed the genotype of two generations of individuals in ten families and concluded that it was not a disease-causing variant since it was found almost with the same frequency in normal and affected individuals, and it didn't modify the phenotype in any of the FAP patients. Furthermore, according to Fernández-Rozadilla et al (22), Asp1822Val is unrelated to CRC development and alleles $\mathrm{T}$ and $\mathrm{A}$ are equally distributed among cases and controls $(\mathrm{P}=0.2197)$ (22). In contrast, in a case-control study in which 1,785 CRC patients and 1,306 controls were analyzed, Picelli et al (23) found that the Asp1822Val polymorphism showed an odds ratio slightly lower in subjects carrying CRC than in controls $(\mathrm{OR}=0.75$, $\mathrm{CI}=0.59-0.94)$, which suggested that the Asp1822Val substitution could protect from CRC (23). Finally, Wong et al (24) evaluated the association between eight $A P C$ single nucleotide polymorphisms and the risk of developing colorectal adenoma 
A

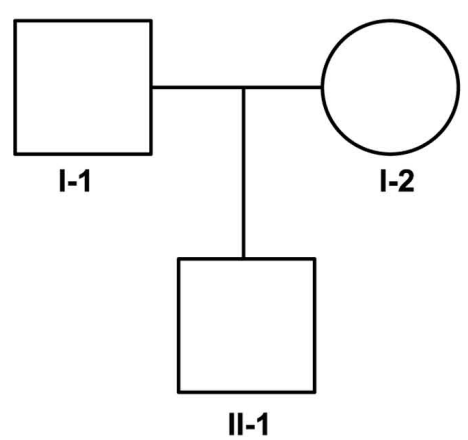

C

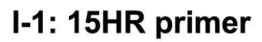

HR primer

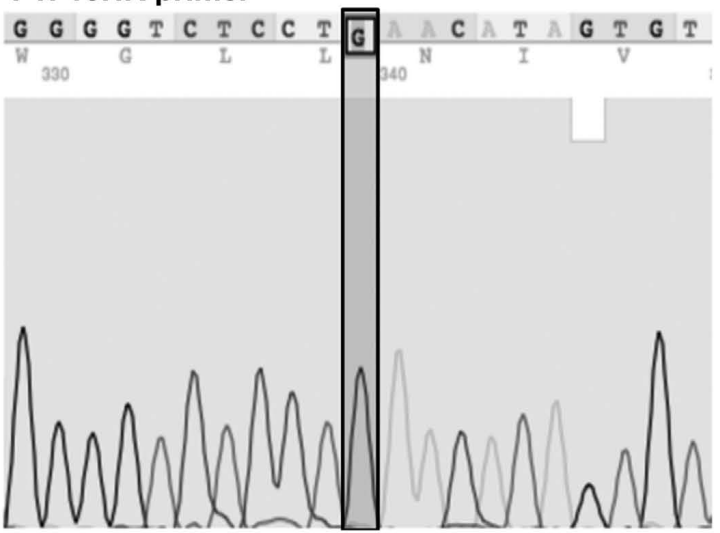

II-1: $15 \mathrm{HF}$ primer

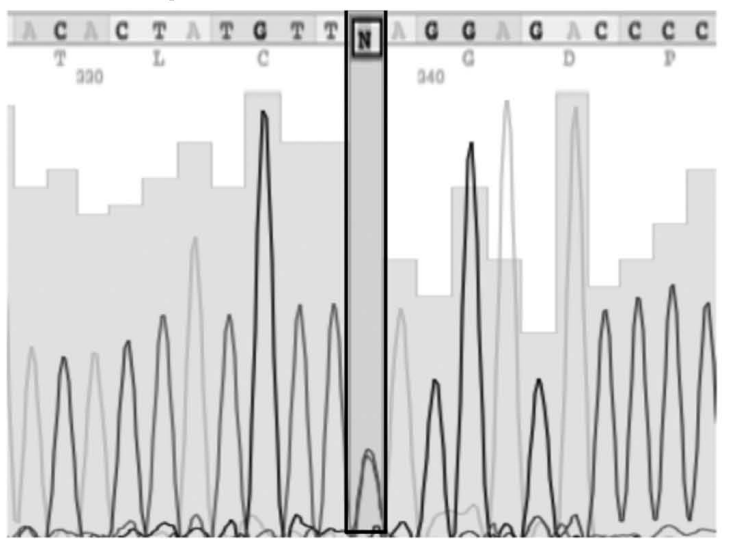

B

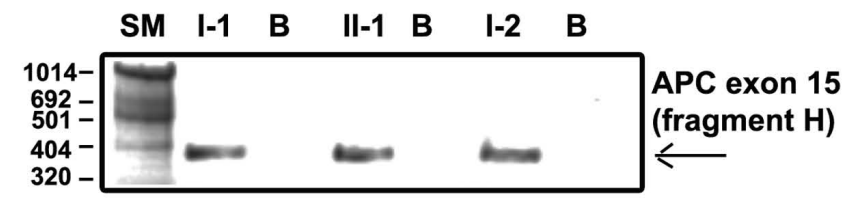

c.4132C $>T$ (p.GIn1378X)

I-2: 15HR primer

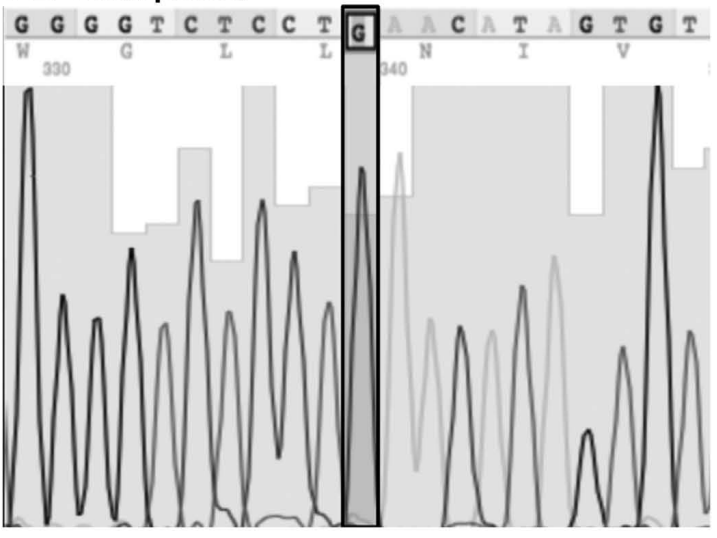

II-1: 15HR primer

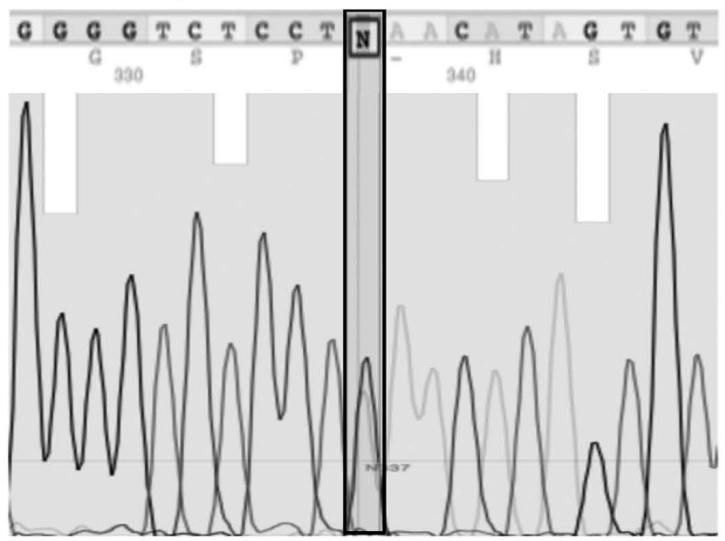

Figure 2. Molecular analysis of c.4132 C>T (p.Gln1378X) variant within the family. (A) Pedigree of the analyzed family. (B) PCR-electrophoresis gel image of exon 15 (fragment $\mathrm{H}$ ) amplified from the proband's and the proband's parents' genomic DNA and (C) sequence analysis of APC exon 15 (fragment $\mathrm{H}$ ) performed on fragments amplified from the genomic DNA of the proband (II.1) and his parents (subjects I-1 and I-2). Electropherograms showing the identified variant c.4132 C>T (p.Gln1378X) are reported. Specific nucleotides at position 4132 are shown in black boxes in each electropherogram. APC, adenomatous poliposis coli; SM, DNA size marker; I-1, II-1 and I-2, amplicons obtained by using DNA template from subjects I-1, II-1 and I-2, respectively; B, blank, PCR negative control performed without DNA template.

and concluded that none of the single nucleotide polymorphisms were associated with an increased risk. However, p. Asp1822Val was reported to influence the risk of colorectal adenoma in individuals with higher fat intake.

In conclusion, we found that the germline Gln1378X APC variant is the cause of a very severe sporadic FAP in the proband analyzed in the present study. Notably, the patient had the initial typical symptoms of the disease at the age of two years, although the clinical diagnosis was made when he was nine years old. Young symptomatic FAP patients have been described previously, but rarely in families with negative family history (25). We reported a severe case of FAP with onset in the toddler years, which represents a de novo pathogenetic variant (9). In both cases, the very young age at initial presentation ( $\sim 2$ years), as well as the absence of a family history of FAP, delayed the diagnosis for many years. Therefore, we reiterate the importance of endoscopic investigation in a child with iron-deficiency anaemia and a history of rectal bleeding should undergo endoscopic investigation notwithstanding no having a family history of FAP.

Further studies are required to determine whether Gln1378X and p.Val1822Asp play an additive role in his FAP phenotypic manifestations or not. 
Table I. Primer pairs used for the genetic analysis of adenomatous poliposis coli exons 1 to 15 .

\begin{tabular}{|c|c|c|}
\hline Primers & Forward sequence $\left(5^{\prime}-3^{\prime}\right)$ & Reverse sequence $\left(5^{\prime}-3^{\prime}\right)$ \\
\hline $1 \mathrm{FP} / \mathrm{RP}$ & AGGTCCAAGGGTAGCCAAGG & TAAAAATGGATAAACTACAATTAAAAG \\
\hline $2 \mathrm{FP} / \mathrm{RP}$ & AAATACAGAATCATGTCTTGAAGT & ACACCTAAAGATGACAATTTGAG \\
\hline $3 \mathrm{FP} / \mathrm{RP}$ & TAACTTAGATAGCAGTAATTTCCC & ACAATAAACTGGAGTACACAAGG \\
\hline $4 \mathrm{FP} / \mathrm{RP}$ & ATAGGTCATTGCTTCTTGCTGAT & TGAATTTTAATGGATTACCTAGGT \\
\hline $5 \mathrm{FP} / \mathrm{RP}$ & CTTTTTTTGCTTTTACTATTAACG & TGTAATTCATTTTATTCCTAATAGCTC \\
\hline $6 \mathrm{FP} / \mathrm{RP}$ & GGTAGCCATAGTATGATTATTTCT & СТАССТАТТTТТАТАСССАСАAАС \\
\hline $7 \mathrm{FP} / \mathrm{RP}$ & AAGAAAGCCTACACCATTTTTGC & GATCATTCTTAGAACCATCTTGC \\
\hline $8 \mathrm{FP} / \mathrm{RP}$ & ACCTATAGTCTAAATTATACCATC & GTCATGGCATTAGTGACCAG \\
\hline $9 \mathrm{FP} / \mathrm{RP}$ & AGTCGTAATTTTGTTTCTAAACTC & TGAAGGACTCGGATTTCACGC \\
\hline 9a FP/RP & TCATTCACTCACAGCCTGATGAC & GCTTTGAAACATGCACTACGAT \\
\hline $10 \mathrm{FP} / \mathrm{RP}$ & AAACATCATTGCTCTTCAAATAAC & TACCATGATTTAAAAATCCACCAG \\
\hline 10a FP/RP & AGACTAGGACTGAGACATTAATCATC & GGTGAGGAGTGAGAAGAAGGTAATC \\
\hline $11 \mathrm{FP} / \mathrm{RP}$ & GATGATTGTCTTTTTCCTCTTGC & CTGAGCTATCTTAAGAAATACATG \\
\hline $12 \mathrm{FP} / \mathrm{RP}$ & TTTTAAATGATCCTCTATTCTGTAT & ACAGAGTCAGACCCTGCCTCAAAG \\
\hline $13 \mathrm{FP} / \mathrm{RP}$ & TTTCTATTCTTACTGCCTAGCATT & ATACACAGGTAAGAAATTAGGA \\
\hline $14 \mathrm{FP} / \mathrm{RP}$ & TAGATGACCCATATTCTGTTTC & CAATTAGGTCTTTTTGAGAGTA \\
\hline $15 \mathrm{~A} \mathrm{FP} / \mathrm{RP}$ & GTTACTGCATACACATTGTGAC & GCTTTTTGTTTCCTAACATGAAG \\
\hline 15B FP/RP & AGTACAAGGATGCCAATATTATG & АСТTСТАТСTTTTTCAGAACGAG \\
\hline $15 \mathrm{C} \mathrm{FP} / \mathrm{RP}$ & ATTTGAATACTACAGTGTTACCC & CTTGTATTCTAATTTGGCATAAGG \\
\hline 15D FP/RP & CTGCCCATACACATTCAAАCAC & TGTTTGGGTCTTGCCATCTT \\
\hline $15 \mathrm{E} \mathrm{FP} / \mathrm{RP}$ & AGTCTTAAATATTCAGATGAGCAG & GTTTCTCTTCATTATATTTTATGCTA \\
\hline $15 \mathrm{~F} \mathrm{FP} / \mathrm{RP}$ & AAGCCTACCAATTATAGTGAACG & AGCTGATGACAAGATGATAATG \\
\hline $15 \mathrm{G} \mathrm{FP} / \mathrm{RP}$ & AAGAAACAATACAGACTTATTGTG & ATGAGTGGGGTCTCCTGAAT \\
\hline $15 \mathrm{H} \mathrm{FP} / \mathrm{RP}$ & ATCTCССТCCAAAAGTGGTGC & TCCATCTGGAGTACTTTCTGTG \\
\hline 15I FP/RP & AGTAAATGCTGCAGTTCAGAGG & CCGTGGCATATCATCCCCC \\
\hline $15 \mathrm{~J} \mathrm{FP} / \mathrm{RP}$ & CCCAGACTGCTTCAAAATTACC & GAGCCTCATCTGTACTTCTGA \\
\hline $15 \mathrm{~K} \mathrm{FP} / \mathrm{RP}$ & CCCTCCAAATGAGTTACGTGA & TTGTGGTATAGGTTTTACTGGTG \\
\hline 15L FP/RP & ACCCAACAAAAATCAGTTAGATG & GTGGCTGGTAACTTTAGCCTC \\
\hline $15 \mathrm{M} \mathrm{FP} / \mathrm{RP}$ & ATGATGTTGACCTTTCCAGGG & ATTGTGTAACTTTTCATCAGTTGC \\
\hline $15 \mathrm{~N} \mathrm{FP} / \mathrm{RP}$ & AAAGACATACCAGACAGAGGG & CTTTTTTGGCATTGCGGAGCT \\
\hline $15 \mathrm{O} \mathrm{FP} / \mathrm{RP}$ & AAGATGACCTGTTGCAGGAATG & GAATCAGACGAAGCTTGTCTAGAT \\
\hline 15P FP/RP & CCATAGTAAGTAGTTTACATCAAG & AAACAGGACTTGTACTGTAGGA \\
\hline 15Q FP/RP & CAGCCCCTTCAAGCAAACATG & GAGGACTTATTCCATTTCTACC \\
\hline 15R FP/RP & CAGTCTCCTGGCCGAAACTC & GTTGACTGGCGTACTAATACAG \\
\hline $15 \mathrm{~S} F \mathrm{FP} / \mathrm{RP}$ & TGGTAATGGAGCCAATAAAAAGG & TGGGAGTTTTCGCCATCCAC \\
\hline $15 \mathrm{~T} \mathrm{FP} / \mathrm{RP}$ & TGTCTCTATCCACACATTCGTC & ATGTTTTTCATCCTCACTTTTTGC \\
\hline 15U FP/RP & GGAGAAGAACTGGAAGTTCATA & TTGAATCTTTAATGTTTGGATTTGC \\
\hline $15 \mathrm{~V} \mathrm{FP/RP}$ & TCTCCCACAGGTAATACTCCC & GCTAGAACTGAATGGGGTACG \\
\hline $15 \mathrm{~W} \mathrm{FP/RP}$ & CAGGACAAAATAATCCTGTCCC & ATTTTCTTAGTTTCATTCTTCCTC \\
\hline
\end{tabular}

FP, forward primer; RP, reverse primer.

\section{Acknowledgements}

The authors would like to thank Dr Jaen Ann Gilder for the text editing.

\section{Funding}

The present study was supported by Università di Napoli Federico II (CTB_ATENEO_2017_DR_3577/2017).
Availability of data and materials

All data generated or analyzed during this study are included in this published article.

\section{Authors' contributions}

MDR and PI designed the study. MDR, AC, AA and FC performed genetic analysis. EM and MR provided sample 
collection and clinical support. MDR and PI contributed to data interpretation. MDR and AC wrote the manuscript, and FD and RL critically revised the manuscript and participated in the analysis and interpretation of the data. All authors read and approved the final manuscript.

\section{Ethics approval and consent to participate}

Written informed consent has been provided by the proband's parents. All methods are part of the clinical practice necessary to carry out the molecular analysis of the APC gene, requested by the proband's parents. Furthermore, the proband's parents agree that the DNA sample no longer needed for the study is used for medical research purposes in an anonymous form and/or in epidemiological cases. The procedures reported in this study were performed in accordance with the rules of the Good Clinical Practice Guidelines (GCP) and the ethical principles set out in the Declaration of Helsinki. The study was also authorized by 'Comitato etico per le attività Biomediche-Carlo Romano of the University of Naples Federico II' (protocol no. 35/17).

\section{Patient consent for publication}

Not applicable. All identifying information, case details, personal information or images that may enable an individual to be identified, are not included in the text.

\section{Competing interests}

The authors declare that they have no competing interests.

\section{References}

1. Ferlay J, Soerjomataram I, Dikshit R, Eser S, Mathers C, Rebelo M, Parkin DM, Forman D and Bray F: Cancer incidence and mortality worldwide: Sources, methods and major patterns in GLOBOCAN 2012. Int J Cancer 136: E359-E386, 2015.

2. De Rosa M, Rega D, Costabile V, Duraturo F, Niglio A, Izzo P, Pace U and Delrio P: The biological complexity of colorectal cancer: Insights into biomarkers for early detection and personalized care. Therap Adv Gastroenterol 9: 861-886, 2016.

3. Ma H, Brosens LA, Offerhaus GJ, Giardiello FM, de Leng WW and Montgomery EA: Pathology and genetics of hereditary colorectal cancer. Pathology 50: 49-59, 2018.

4. Fearnhead NS, Britton MP and Bodmer WF: The ABC of APC. Hum Mol Genet 10: 721-733, 2001.

5. De Rosa M, Galatola M, Borriello S, Duraturo F, Masone S and Izzo P: Implication of adenomatous polyposis coli and MUTYH mutations in familial colorectal polyposis. Dis Colon Rectum 52: 268-274, 2009.

6. Half E, Bercovich D and Rozen P: Familial adenomatous polyposis. Orphanet J Rare Dis 4: 22, 2009.

7. Groden J, Thliveris A, Samowitz W, Carlson M, Gelbert L, Albertsen H, Joslyn G, Stevens J, Spirio L, Robertson M, et al: Identification and characterization of the familial adenomatous polyposis coli gene. Cell 66: 589-600, 1991.

8. Leoz ML, Carballal S, Moreira L, Ocaña T and Balaguer F: The genetic basis of familial adenomatous polyposis and its implications for clinical practice and risk management. Appl Clin Genet 8: 95-107, 2015.
9. Auricchio R, De Rosa M, Quaglietta L, Miele E, Boccia G, Staiano A and Izzo P: A dramatic case of early-onset familial adenomatous polyposis. Clin Genet 67: 104-106, 2005.

10. Aoki K and Taketo MM: Adenomatous polyposis coli (APC): A multi-functional tumor suppressor gene. J Cell Sci 120: 3327-3335, 2007.

11. Polakis P: The adenomatous polyposis coli (APC. tumor suppressor. Biochim Biophys Acta 1332: F127-F147, 1997.

12. Dodaro C, Grifasi C, Florio J, Santangelo ML, Duraturo F, De Rosa M, Izzo P and Renda A: The role of mutation analysis of the APC gene in the management of FAP patients. A controversial issue. Ann Ital Chir 87: 321-325, 2016.

13. Galatola M, Paparo L, Duraturo F, Turano M, Rossi GB, Izzo P and De Rosa M: Beta catenin and cytokine pathway dysregulation in patients with manifestations of the 'PTEN hamartoma tumor syndrome'. BMC Med Genet 13: 28, 2012.

14. Nagase H and Nakamura Y: Mutations of the APC (adenomatous polyposis coli) gene. Hum Mutat 2: 425-434, 1993.

15. Gayther SA, Wells D, SenGupta SB, Chapman P, Neale K, Tsioupra K and Delhanty JD: Regionally clustered APC mutations are associated with a severe phenotype and occur at a high frequency in new mutation cases of adenomatous polyposis coli. Hum Mol Genet 3: 53-56, 1994.

16. De Rosa M, Scarano MI, Panariello L, Carlomagno N, Rossi GB, Tempesta A, Borgheresi P, Renda A and Izzo P: Three submicroscopic deletions at the APC locus and their rapid detection by quantitative-PCR analysis. Eur J Hum Genet 7: 695-703, 1999.

17. Newton KF, Mallinson EK, Bowen J, Lalloo F, Clancy T, Hill J and Evans DG: Genotype-phenotype correlation in colorectal polyposis. Clin Genet 81: 521-531, 2012.

18. Fostira F, Thodi G, Sandaltzopoulos R, Fountzilas G and Yannoukakos D: Mutational spectrum of APC and genotype-phenotype correlations in Greek FAP patients. BMC Cancer 10: 389, 2010.

19. Liu X, Shan X, Friedl W, Uhlhaas S, Propping P, Li J and Wang Y: May the APC gene somatic mutations in tumor tissues influence the clinical features of Chinese sporadic colorectal cancers? Acta Oncol 46: 757-762, 2007.

20. Friedl W and Aretz S: Familial adenomatous polyposis: Experience from a study of 1164 unrelated german polyposis patients. Hered Cancer Clin Pract 3: 95-114, 2005.

21. De Rosa M, Scarano MI, Panariello L, Salvatore F and Izzo P: A novel Mbo II polymorphism in exon 15 of the human adenomatous polyposis coli gene. Clin Genet 53: 315-316, 1998.

22. Fernández-Rozadilla C, de Castro L, Clofent J, Brea-Fernández A, Bessa X, Abulí A, Andreu M, Jover R, Xicola R, Llor X, et al: Single nucleotide polymorphisms in the Wnt and BMP pathways and colorectal cancer risk in a spanish cohort. PLoS One 5: e12673, 2010.

23. Picelli S, Zajac P, Zhou XL, Edler D, Lenander C, Dalén J, Hjern F, Lundqvist N, Lindforss U, Påhlman L, et al: Common variants in human CRC genes as low-risk alleles. Eur J Cancer 46: 1041-1048, 2010.

24. Wong HL, Peters U, Hayes RB, Huang WY, Schatzkin A, Bresalier RS, Velie EM and Brody LC: Polymorphisms in the adenomatous polyposis coli (APC) gene and advanced colorectal adenoma risk. Eur J Cancer 46: 2457-2466, 2010.

25. Septer S, Lawson CE, Anant S and Attard T: Familial adenomatous polyposis in pediatrics: Natural history, emerging surveillance and management protocols, chemopreventive strategies, and areas of ongoing debate. Fam Cancer 15: 477-485, 2016. 